\title{
Addition to the knowledge of Cyphomyiactia costai Artigas, Papavero \& Serra, 1991 (Asilidae, Laphriinae, Atomosiini): description of the male, and illustration of the holotype and structures of male and female terminalia
}

\author{
Rodrigo Vieira ${ }^{1,2,5}$ \& Lucas de Araújo Cezar ${ }^{3,4,6}$ \\ 1 Secretaria de Estado de Educação e Qualidade de Ensino do Amazonas (SEDUC/Amazonas). Manaus, AM, Brasil. \\ 2 Instituto Nacional de Pesquisas da Amazônia (INPA), Coordenação de Biodiversidade (CBIO), \\ Programa de Pós-Graduação em Entomologia (PPG-ENT). Manaus, AM, Brasil. \\ ${ }^{3}$ Universidade de São Paulo (USP), Museu de Zoologia (MZUSP). São Paulo, SP, Brasil. \\ ${ }^{4}$ Universidade de São Paulo (USP), Faculdade de Filosofia, Ciências e Letras de Ribeirão Preto (FFCLRP), \\ Programa de Pós-Graduação em Entomologia. Ribeirão Preto, SP, Brasil. \\ ${ }^{5}$ ORCID: 0000-0002-3382-9638. E-mail: rodrigo08vieira@gmail.com \\ ${ }^{6}$ E-mail: lucasilidae@gmail.com
}

\begin{abstract}
The male of Cyphomyiactia costai Artigas, Papavero \& Serra, 1991 is described and illustrated for the first time. New records are provided from the states of Bahia, Maranhão and Mato Grosso, Brazil. The holotype is illustrated, as well as structures of male and female terminalia.
\end{abstract}

Key-Words. Asiloidea; Neotropical; Cyphomyia.

\section{INTRODUCTION}

Artigas, Papavero \& Serra (1991) proposed the genus Cyphomyiactia to include an undescribed Brazilian species, Cyphomyiactia costai Artigas, Papavero \& Serra, 1991, because of its singular morphology. The generic description was based on a single female specimen collected in Goiás state.

Cyphomyiactia costai possesses a relatively wide face and an evenly convex, first flagellomere prolonged into a filiform process; the abdomen is very wide; short, and cup-shaped. Due to the overall coloration, the body being blackish with blue reflections and with a golden tomentose occiput, these robber-flies resemble stratiomyids of the genus Cyphomyia Wiedemann (Artigas, Papavero \& Serra, 1991).

In this work, the male of Cyphomyiactia costai Artigas, Papavero \& Serra, 1991 is described and illustrated for the first time. New records are provided from Bahia and Maranhão states, Brazil. The holotype is illustrated, as well as structures of male and female terminalia.

\section{MATERIALS AND METHODS}

In the present study, we examined specimens housed at INPA - Instituto Nacional de Pesquisas da Amazônia, CEIOC - Coleção Entomológica do Instituto Oswaldo Cruz, and CZMA - Coleção Zoológica do Maranhão, Universidade Estadual do Maranhão, Caxias, Maranhão, Brasil, as well as the holotype of $C$. costai housed in the Museu de Zoologia da Universidade de São Paulo (MZUSP) collection.

General morphological terminology follows Cumming \& Wood (2009).

Dissected terminalia were treated in hot $10 \%$ $\mathrm{KOH}$ for varying periods of time, washed in water, subsequently treated in acetic acid and finally examined in excavated slides in glycerin. Illustrations of the terminalia were prepared using Adobe Illustrator CS5 software. After examination and illustration, the detached parts were placed in microvials containing glycerin and the vials were pinned with their respective specimens. Images were taken with a ZEISS AxioCam 


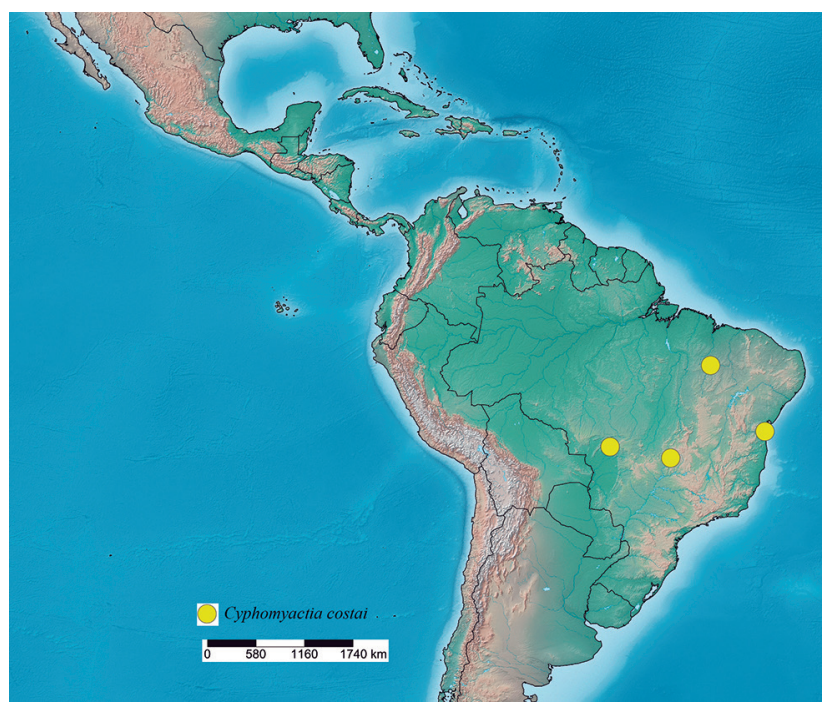

Figure 1. Distribution of Cyphomyiactia costai.

Mrc5 digital camera attached to a Zeiss Discovery V20 Stereomicroscope, using the lighting methods described by Kerr et al. (2008). Focus stacks of photos of asilid specimens were combined using CombineZP (Hadley, 2010).

Label data is cited in full, with the original spellings, punctuations, and dates. Information presented within square brackets - "[ ]" - is complementary data not included on the labels. Data for the same specimen but from different labels are separated by slashes ().

The map was generated on the website SimpleMappr (www.simplemappr.net) (Fig. 1).

\section{Cyphomyiactia costai Artigas, Papavero \& Serra, 1991} (Figs. 2-3)

Cyphomyiactia costai Artigas, Papavero \& Serra, 1991: 62; Papavero, 2009: 92 (catalogue).

\section{Original description is transcribed below:}

"Face densely silvery-white tomentose. Hair of mystax white [Fig. 2C]. Occiput [Fig. 2D] golden tomentose at margins, brownish-black tomentose around foramen, with long, sparse, fine white pile bellow; dorsal occipital bristles yellowish. Scape brown, pedicel brownish-yellow, flagellum red-brown and white pollinose [Figs. 2C, 2D]. Frons golden tomentose with a slender black stripe running from anterior ocellus to base of antennae. Vertex black.

Thorax blackish in ground color, with bluish reflections [Fig. 2B]. Pleura with mixed silvery-white and golden-brown tomentum in some areas. Antepronotum predominantly golden tomentose with a brownish-black stripe on the anterior border and yellow hairs. Lateral margins of antepronotum silvery-white tomentose. Postpronotum brown- ish-golden tomentose, hairs brown [Fig. 2C]. Proepisternum silvery-white tomentose, as well as the anepisternum, which shows a polished brown spot and brown hairs. Anepimeron brown, with white pollinosity. Anatergite goldish-silvery-white pollinose with a fringe of yellowish hairs behind posterior callus. Meron brown, white pollinose, with a few brown hairs. Katatergite brown, silvery-white tomentose, with brown bristles. Posterior callus brown.

Wings [Fig. 2F] hyaline, slightly fumose along veins. Halteres yellow.

Abdomen [Figs. 2A, 2B, 2E] blackish in ground color, with blue shine. Hairs of abdomen white. Tergites 3-4 silvery-white tomentose spots dorsolaterally [Fig. 2E].

Holotype female. BRAZIL, Goiás, Goiânia (Campinas), 1935 (Borgmeier \& Souza Lopes), in the MZUSP."

Addenda to the holotype female description: Total length, excluding antenna, $10.6 \mathrm{~mm}$; length of wing, $8.8 \mathrm{~mm}$; greatest width of abdomen, $3.4 \mathrm{~mm}$. Head: Eyes greenish; occiput silvery-golden-pollinose on ventral 1/4. Thorax: Postpronotum with mixed brownish-golden and silvery-white tomentum, setae brown and white (Fig. 2C); anepisternum with mixed silvery-white and golden-brown tomentum; 3 long and strong anepisternal macrosetae, among others; anepimeron dark-brown; 3 postalar setae (not 1 postalar +3 on "posterior callus"). Wing (Fig. 2F): Cell c wide; $r_{5}$ closed, with short stalk; $\mathrm{m}_{3}$ widening posteriorly; cup with short stalk; anal lobe wide. Legs (Figs. 2A-2C, 2E): Entirely dark-brown, with dark-brown setae; tarsi with golden vestiture.

Label transcript: “Campinas, Goyaz [Goiás], Borgmeier et. S. Lopes, XII.[1]935 / [handwritten] Cyphomyiactia cyphomyioides, gen. n. sp. n. Artigas, Papavero \& Serra / [red label] HOLOTYPE Cyphomyiactia costai, det. L.A. Cezar, 2014."

Holotype condition: Pinned; well preserved; lacking right antenna, anepisternal and postalar setae on the left side, and left wing.

Female, additional specimen: Total length, excluding antenna, $9.2 \mathrm{~mm}$; length of wing, $7.1 \mathrm{~mm}$; greatest width of abdomen, $3.2 \mathrm{~mm}$.

Female terminalia, additional specimen (Figs. 3A-3C): Anterior margin of sternite VII sinuous (Fig. 3A); hypogynium almost hemispherical, with hypogynial valves continuous with lateral margins of the sclerite (Fig. 3 C); smooth median protrusion between hypogynial valves (Fig. 3C); smooth retraction on anterior margin (Fig. 3C); hypogynium softly setate posteriorly. Three sperma- 
thecae (Fig. 3B), occupying abdominal segments 4-8; reservoirs cylindrical, disposed from a wider elliptical spiral going to an inner round and more sclerotized spiral distally (Fig. 3B); spermathecal ducts opening independently at the bursa; genital fork U-shaped, arms anteriorly thick, posteriorly truncate, divergent (Fig. 3B). Eggs brown and oval.

Male (Figs. 3D-3I): Total length, excluding antenna, $10.6 \mathrm{~mm}$; length of wing, $7.6 \mathrm{~mm}$; greatest width of abdo-

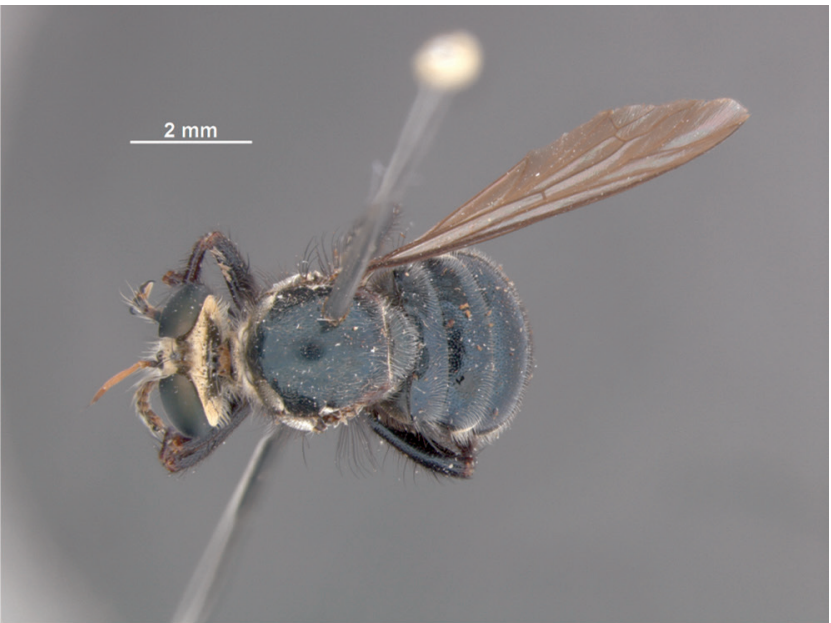

B

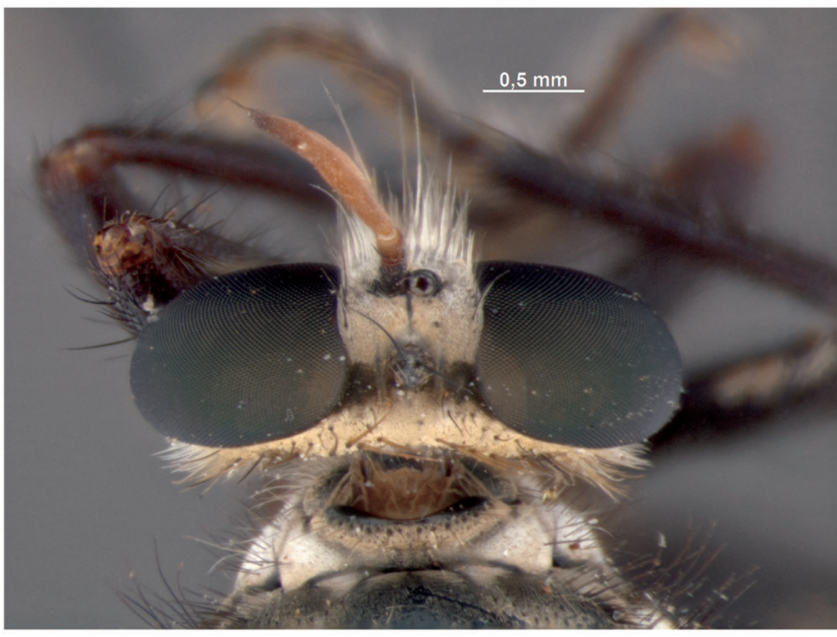

D

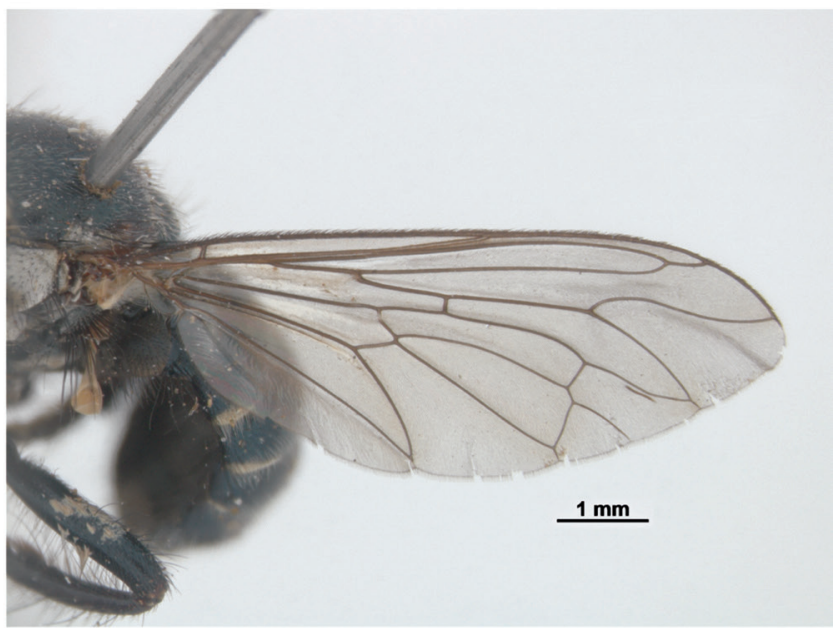

$\mathbf{F}$

Figure 2. Cyphomyiactia costai Holotype female. (A) Habitus, lateral view; (B) Habitus, dorsal view; (C) Head, lateral view; (D) Head, dorsal view; (E) Abdomen, lateral view; (F) Wing. 


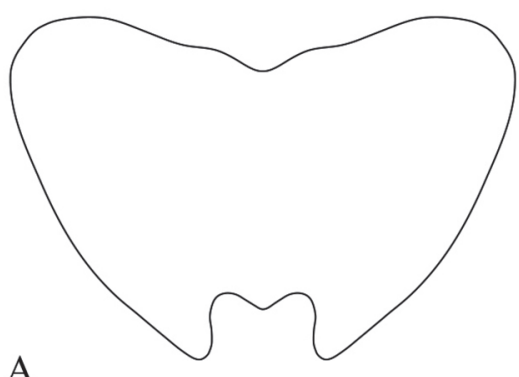

A
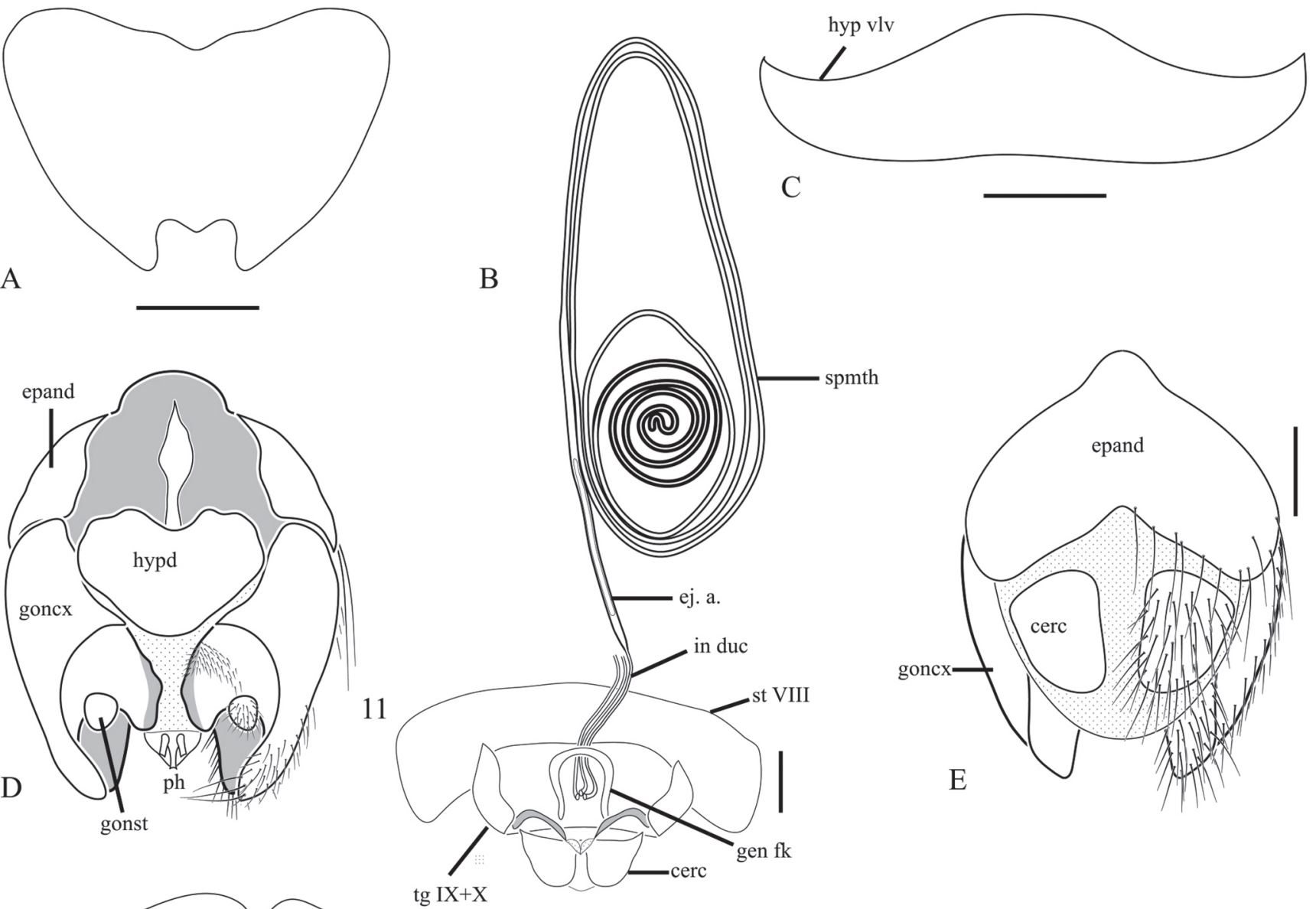

$\operatorname{tg} I X+X$
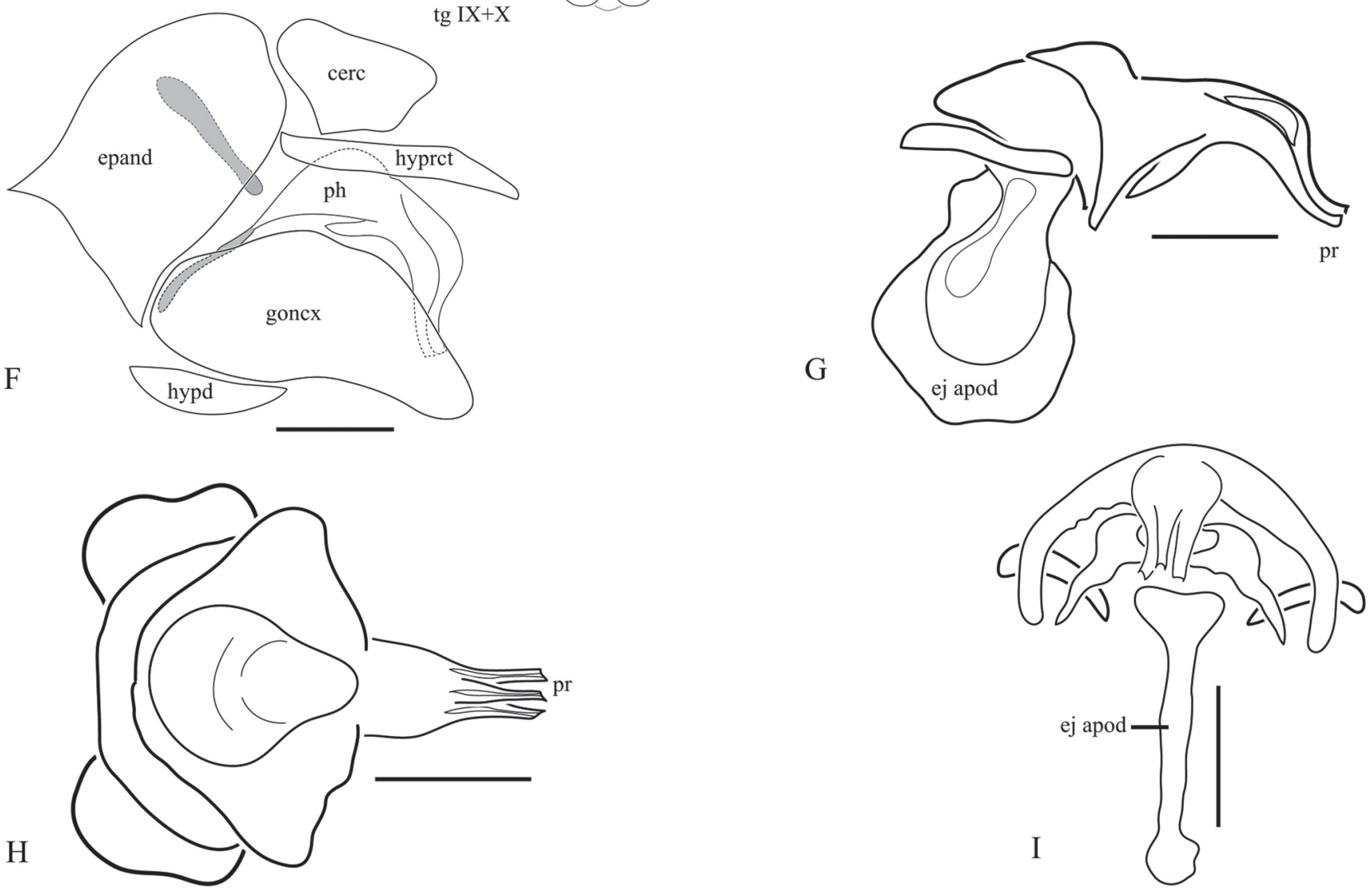

Figure 3. Cyphomyiactia costai. Addtional specimen. (A) Female, sternite VII; (B) Female genitalia; (C) Female, sternite VIII; (D) Male terminalia, ventral view; (E) Male terminalia, dorsal view; (F) Male terminalia, lateral view; (G) Phallus, lateral view; (H) Phallus, ventral view; (I) Phallus, dorsal view. Abbreviations: cerc: cercus; ej a: ejection apparatus; ej apod: ejaculatory apodeme; epand: epandrium; gen fk: genital fork; goncx: gonocoxite; gonst: gonostylus; hyprct: hypoproct; hypd: hypandrium; hyp hlv: hypoginial valves; in duc: individual duct; ph: phallus; pr: phallic prongs; st VIII: sternite VIII; tg IX + X: tergite IX +X. Scale bar = $1 \mathrm{~mm}$. 
men, $3.2 \mathrm{~mm}$. Similar to female except for: postalar callus with 4 macrosetae; antepronotum predominantly with dark-brown setae; anepimeron with white and brown tomentum. Male Terminalia: Hypopygium inconspicuous in both dorsal and lateral views, hidden under a strongly-convex cup-shaped abdomen. Hypandrium subtriangular, wider than long, with blunt posterior margin, and a median concavity on anterior margin (Fig. 3D). Gonocoxites free, with setae near median margin basally (Fig. 3D); gonocoxal prolongations blunt, smoothly curved inwards, with strong medially-directed setae near apex; gonostyli reduced, round, attached to the dorsal base of gonocoxites (Fig. 3D). Lateral lobes of hypoproct subquadratic (abruptly blunt and parallel-sided), in dorsal view; lateral lobes long, extending beyond the apex of gonocoxal prolongation, and diverging posteriorly. Cerci free, subtriangular, slightly longer than wide, distant from each other (Figs. 3E, 3F). Phallus strongly arched laterally (towards gonocoxal apodemes), protruded mediodorsally, in lateral view (Fig. 3G); moderate dilation proximal to the prongs (Fig. 3G); apex of phallus with three short prongs (Fig. $3 \mathrm{H}$ ); lateral ejaculatory processes wide (Fig. 3I).

Remarks: The specimen deposited in MZUSP did not bear an explicit label clarifying its name-bearing status. Apart from the original specimen label, there was only a handwritten identification label that read "Cyphomyiactia cyphomyioides gen. n. sp. n. Artigas, Papavero \& Serra". Given that the morphology and sampling data of this specimen agree with those cited by the authors in the original description, and that there was no other specimen mentioned for the species in the original work, it is sensible to assume that "C. cyphomyioides" is an unavailable manuscript name and that this specimen is indeed the holotype of C. costai (N. Papavero, pers. comm.).

Although Cyphomyiactia's singular compactness cannot be identified in any other group within the Atomosiini, its spermathecal disposal greatly resembles that of Hybozelodes lucidus (Hermann, 1912), as well as the shape of antennae, the bluish reflections of thorax and abdomen, and the length of the lateral lobes of hypoproct of the male. These characters could indicate a closer relationship between the monotypic genus Cyphomyiactia and Hybozelodes Hermann, 1912.

Additional material examined: BRASIL, MA[ranhão], Mirador, Parque Est.[adual] Mirador, Base da Geraldina [06 $\left.{ }^{\circ} 43^{\prime} \mathrm{S} 4^{\circ} 4^{\circ} 58^{\prime} \mathrm{W}\right]$ / Armadilha Malaise, 15-26.x.2006,
F. Limeira-de-Oliveira (1 male INPA); same data, except 17.xii.2006 (1 female CZMA); BR[ASIL], BA[HIA],

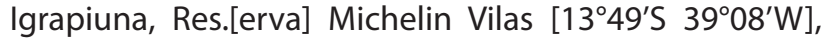
Malaise / 20.i-24.ii.2013, M. Menezes \& E. Aragão col. (1 male INPA); Campinas [Goiânia] [16 $40^{\prime} \mathrm{S} 49^{\circ} 15^{\prime} \mathrm{W}$ ] Goyas [Goiás], [BRASIL] Borgmeier et S. Lopes, xii. [1]925 / Atractia / Det. S.H. Lopes (1 male CEIOC); Chapada dos Guimarães [15⒉ $27^{\prime} 39^{\prime \prime S} 55^{\circ} 45^{\prime} 00^{\prime \prime W}$ ], Mato Grosso, BRASIL, xi. 1963, Alvarenga e Werner (1 male CEIOC).

Distribution (Fig. 1): BRAZIL (Maranhão, Bahia, Goiás, Mato Grosso).

\section{ACKNOWLEDGMENTS}

To the curators of the collections housing the examined material, Dr. Francisco Limeira-de-Oliveira (CZMA), Dr. Carlos Lamas (MZUSP), Dra. Jane Costa (CEIOC) and Dr. Marcio Oliveira (INPA). To Alexssandro Camargo for the records of specimens deposited at CEIOC. To CNPq: Biodiversidade e Monitoramento do processo de desmatamento do cerrado maranhense no Parque Estadual do Mirador, 457440/2012-0 - CNPq PPBio Rede Cerrado; Riqueza, Diversidade e Composição dos táxons de insetos do Parque Estadual do Mirador, estado do Maranhão, Brasil, FAPEMA, Processos: APP-00852/10 - FAPEMA; APP-00498/12 - FAPEMA; CBIOMA-03001/12 - FAPEMA. To CNPq for the fellowships that have allowed us to complete this work. Thanks to anonymous referees for valuable comments that greatly improved the manuscript.

\section{REFERENCES}

Artigas, J.N.; Papavero, N. \& Serra, A.L. 1991. The American genera of Asilidae (Diptera): Keys for identification with an atlas of female spermathecae and other morphological details. VI. Tribe Atomosiini Hermann (Laphriinae), with descriptions of two new genera and three new species, and a catalogue. Gayana Zoologia, 55(1): 53-85.

Cumming, J.M. \& Wood, D.M. 2009. Adult morphology and terminology [Chapter] 2. In: Brown, B.V.; Borkent, A.; Cumming, J.M.; Wood, D.M.; Woodley, N.E. \& Zumbado, M.A. (Eds.). Manual of Central American Diptera. Ottawa, National Research Council Research Press. v. 1, p. 9-50.

Hadley, A. 2010. CombineZP Image Stacking Software. Disponível em: $\underline{\text { https:// }}$ combinezp.software.informer.com.

Kerr, P.H.; Fisher E.M. \& Buffington M.L. 2008. Dome lighting for insect imaging under a microscope. American Entomologist, 54(4): 198-200.

Papavero, N. 2009. Catalogue of Neotropical Diptera. Asilidae. Neotropical Diptera, 17: 1-179. 